PRODUCTIVITY ANALYSIS OF THE TABLE FORMWORK METHOD FOR MAKING A COST-EFFICIENT EQUIPMENT INPUT PLAN

J. B. Kwon, H. S. Lim, T. H. Kim, M. S. Cha, *H. H. Cho and K. I. Kang

School of Civil, Environmental and Architectural Engineering

Korea University

Seoul, Republic of Korea

(*Corresponding author: hhcho@korea.ac.kr) 


\title{
PRODUCTIVITY ANALYSIS OF THE TABLE FORMWORK METHOD FOR MAKING A COST-EFFICIENT EQUIPMENT INPUT PLAN
}

\begin{abstract}
For improvement in the productivity of tall building projects, table formwork is one of the main methods that have been adopted for slab formwork. Because the table formwork method is an equipment-oriented construction method, the type of lifting equipment and method of operation considerably affects the productivity and cost of the table formwork. It is also important to make an equipment input plan for completing the table formwork within the time given, according to the structural construction cycle. For performing the table formwork, a tower crane or an independent lifting system, and shifting trolleys, are required. However, if an inefficient equipment input plan is made, exorbitant cost may be incurred. Therefore, the purpose of this study is to analyze the productivity of a table formwork, considering the type and number of lifting equipment and the number of trolleys inputted, and to suggest quantitative data for making a cost-efficient equipment input plan within the construction duration given. It is expected that the results of this research will be utilized as a basis for cost-efficient equipment input planning.
\end{abstract}

\section{KEYWORDS}

Tall building, Tower crane, Independent lifting system, Productivity analysis, Simulation, CYCLONE

\section{INTRODUCTION}

For improvement in the productivity of tall building projects, table formwork is one of the main methods that have been adopted for slab formwork. Because the table formwork method is an equipment-oriented construction method, the type of lifting equipment and method of operation considerably affect the productivity and cost of the table formwork. It is also important to make an equipment input plan for completing the table formwork within the time given, according to the structural construction cycle.

The table formwork method generally requires a Tower Crane (T/C) or independent lifting system for lifting the table form, and shifting trolleys for moving the table form. The table formwork with T/C will increase the lifting load of the T/C. However, when using an independent lifting system, more efficient lifting will be possible, in spite of the expensive cost. Consequently, the table formwork requires an equipment input plan that considers the cost and duration adequate to the table formwork. However, due to the lack of performance-data, it is difficult to figure out its quantitative effect and cost. Thus project managers have difficulty in deciding the type and number of lifting equipment input following the formwork.

The purpose of this study is to analyze the productivity of table formwork considering the type and number of lifting equipment, and the number of trolleys inputted, using Web-CYCLONE, and to suggest quantitative data for making a cost-efficient equipment input plan within the construction duration given. The targets of the analysis are the table formwork method with T/C, using the loading platform, and the table formwork with Table Lifting System (TLS), as developed by DOKA GmbH. It is expected that the results of this research will be utilized as a basis for cost-efficient equipment input planning. 


\section{LIFTING EQUIPMENT FOR TABLE FORMWORK}

\section{Tower crane}

A table formwork with T/C lifts the table forms by loading them onto a loading platform, located on an external wall of the building (Fig. 1). It is necessary to use a shifting trolley that can strip and install the table forms on the stripping floor. To maintain the balance of the table form, wire should be tied to the four corners of the table form. The table form tied with wire is quickly lifted to the place of installation through the T/C, and additional equipment for installing the table form is not required.
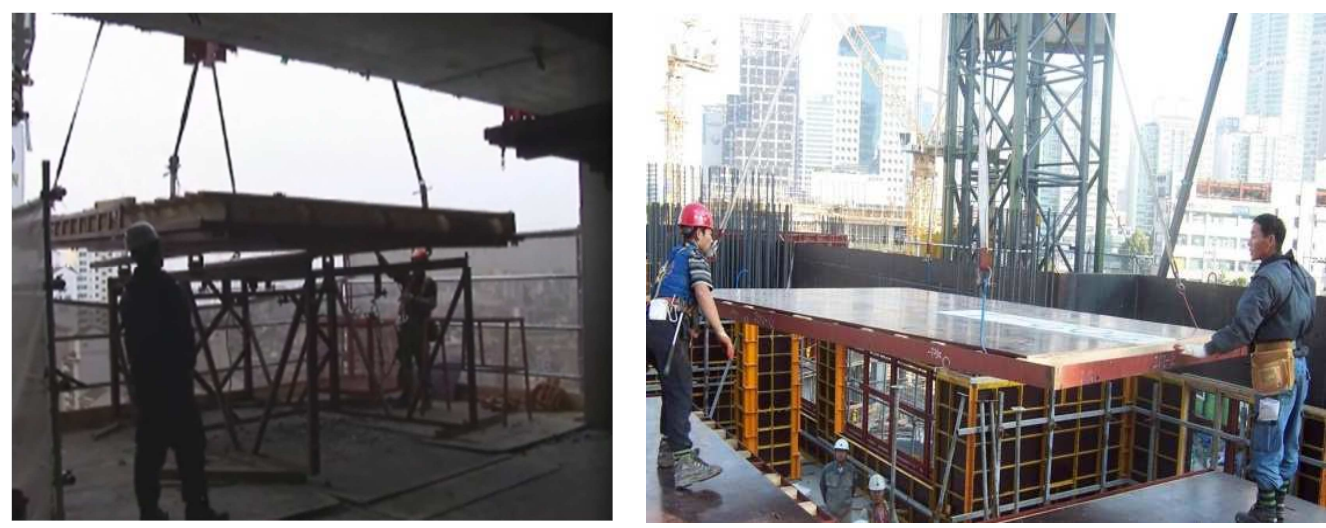

Figure 1 - Lifting and installing work with T/C

However, this lifting method requires additional time for tying the wire, and work skill of the T/C driver in using the table formwork (Kim, 2013). Furthermore, higher heights of buildings lead to more difficulty in the lifting work, due to the effects of wind. The installation time of the next table form is also delayed, because the T/C should be used during the installation duration of the table form.

\section{TLS (Table Lifting System)}

The Table Lifting System (TLS), developed by DOKA GmbH, is a system for the vertical lifting of table forms, with no need for a T/C (DOKA GmbH, 2011). The system can lift the table form at a speed of $10 \mathrm{~m} / \mathrm{min}$, through an independent deck that is supported by two masts, between the stripping and installing floors. For use in a building of any height, the system can automatically raise itself using hydraulic power on the external wall of a building, and can run at high wind loads (of up to $20 \mathrm{~m} / \mathrm{sec})$. 


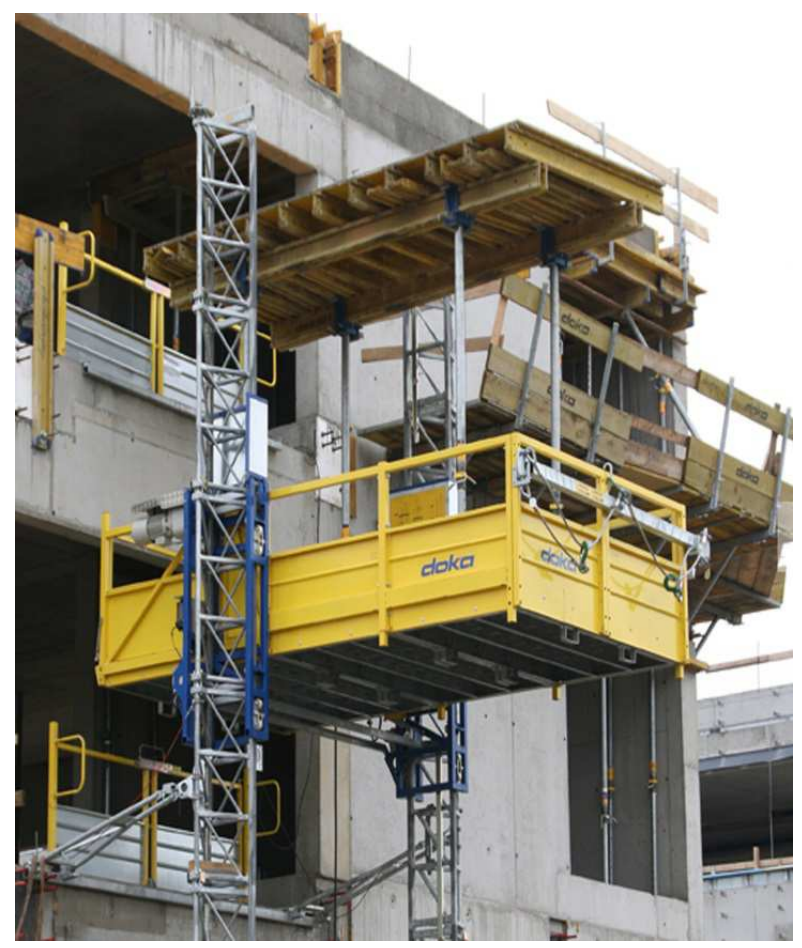

Figure 2 - Table Lifting System developed by DOKA GmbH

The table formwork with TLS, in contrast to the table formwork with T/C, requires one or more shifting trolleys on the installing floor. The system can lift the next table form, because of the shifting trolley on the installing floor, regardless of travel or the installation time of the table form. Therefore, the stripping and installing work of a table form is conducted separately. This formwork method can improve the productivity of table formwork, and reduce the lifting load of the T/C.

\section{CYCLONE MODELING BY LIFTING EQUIPMENT}

\section{Project overview}

To measure the productivity of the table formwork method by applying two different items of lifting equipment, a case site of a tall building construction project was considered, where table formwork was being used. The case site was a construction field in Busan, Korea, for a high-rise 63floor office building, where table formwork lasting 18 months was planned. The table formwork was conducted by dividing the construction site into zones A and B for a 4-day cycle, and a total of 99 table form units were used, which were composed of 48 and 51 table form units for each zone, respectively, to form three floors. One TLS was used for lifting the table form in each zone, and two shifting trolleys were installed on each stripping and installing floor.

\section{CYCLONE model for table formwork with T/C}

The table form process with T/C was investigated through a progress schedule corresponding to the case site, and with interviews with the project manager. The table formwork process with T/C was categorized into stripping work using a shifting trolley, and installing work with the T/C. In the stripping step, the table form is stripped, and shifted to the loading platform, using a shifting trolley. The table form is loaded onto the loading platform, and then tied to the wires of the T/C. After the tying work, the shifting trolley is returned to the stripping spot, for stripping the next table form. In the installing step, the table form is lifted to the installing spot, using the T/C. An installation crew conducts the positioning, installing, and untying work. After the untying work, the T/C is returned to the loading platform, to lift the next table form. The details of the simulation model are shown in Figure 3. 


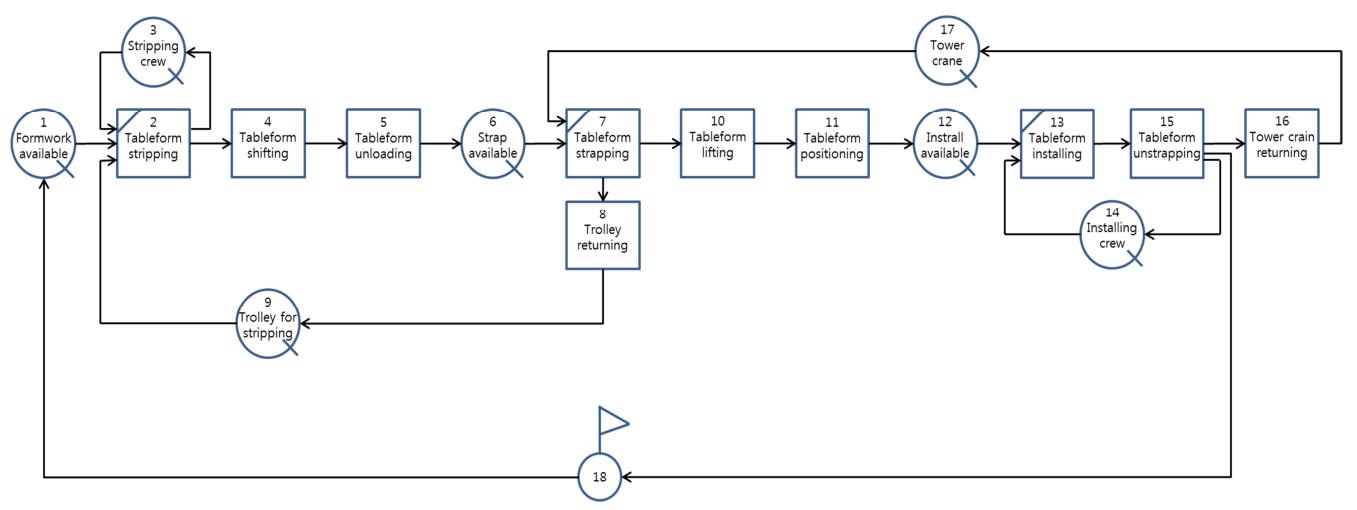

Figure 3 - Simulation model for table formwork with tower crane

The resources for each activity were input on the basis of data collected from the case site. The resources that were input were defined as fifty-one table form units, a pair of installation crews, a pair of stripping crews, a T/C, and two shifting trolleys for stripping table forms. The work time for the simulation was input on the basis of data collected from cameras at the case site. However, since a T/C was not used for lifting the table forms, the lifting time was calculated by the Hook Travel time suggested by Zhang et al. (1999). Also, the travel time of a shifting trolley was calculated by the average duration of table form unit shifting suggested by Lim et al. (2013). Each work time required is described in Table 1.

The work time of installing and stripping the table form were input as triangular distributions, with actual measurements. The lifting and traveling duration of the table form, and the returning duration of the shifting trolley, were input as uniform distribution, according to the distance of traveling and lifting of the table form. The duration for loading, unloading, and tying were defined as deterministic values, because of the almost fixed durations, with little variation.

Table 1 - Duration input data of Table formwork with T/C

\begin{tabular}{lllccc}
\hline \multirow{2}{*}{ Node } & Work task & Value type & \multicolumn{3}{c}{ Duration (min) } \\
\cline { 3 - 6 } & & & Min & Mean & Max \\
\hline 2 & Table form stripping & Triangular & 1 & 2.24 & 3.83 \\
4 & Table form shifting & Uniform & 0.488 & & 5.126 \\
5 & Table form unloading & Deterministic & & 1 & \\
7 & Table form strapping & Deterministic & & 1.5 & \\
8 & Trolley returning & Uniform & 0.488 & & 5.126 \\
10 & Table form lifting & Uniform & 0.36 & & 0.721 \\
11 & Table form positioning & Deterministic & & 1.5 & \\
13 & Table form installing & Triangular & 3.65 & 4.88 & 6.33 \\
15 & Table form unstrapping & Deterministic & & 1 & \\
16 & Tower crane returning & Uniform & 0.36 & & 0.721 \\
\hline
\end{tabular}




\section{CYCLONE model for table formwork using TLS}

In order to analyze the productivity of the table formwork process with TLS, the CYCLONE model suggested by Lim et al. was used (2013). Figure 4 describes the formwork process. Two shifting trolleys were input, both in the installing and stripping steps, and the process was classified into stripping, lifting, and installing steps. In the stripping step, the table form process and the stripping process with T/C were the same, and the tying work of the table form was replaced by fixing work, which is a simpler process. In the lifting step, the table form was lifted with the TLS to the installing floor. After the table form had done the unfixing work, the TLS was returned to the stripping floor, for lifting of the next table form. In the installing step, the unfixed table form traveled, and was unloaded at the installing spot by the shifting trolley. When the unloading was complete, the table form was installed by the installation crew, and the shifting trolley was returned to the TLS, for loading the next table form. The details of the simulation model are described in Figure 4.

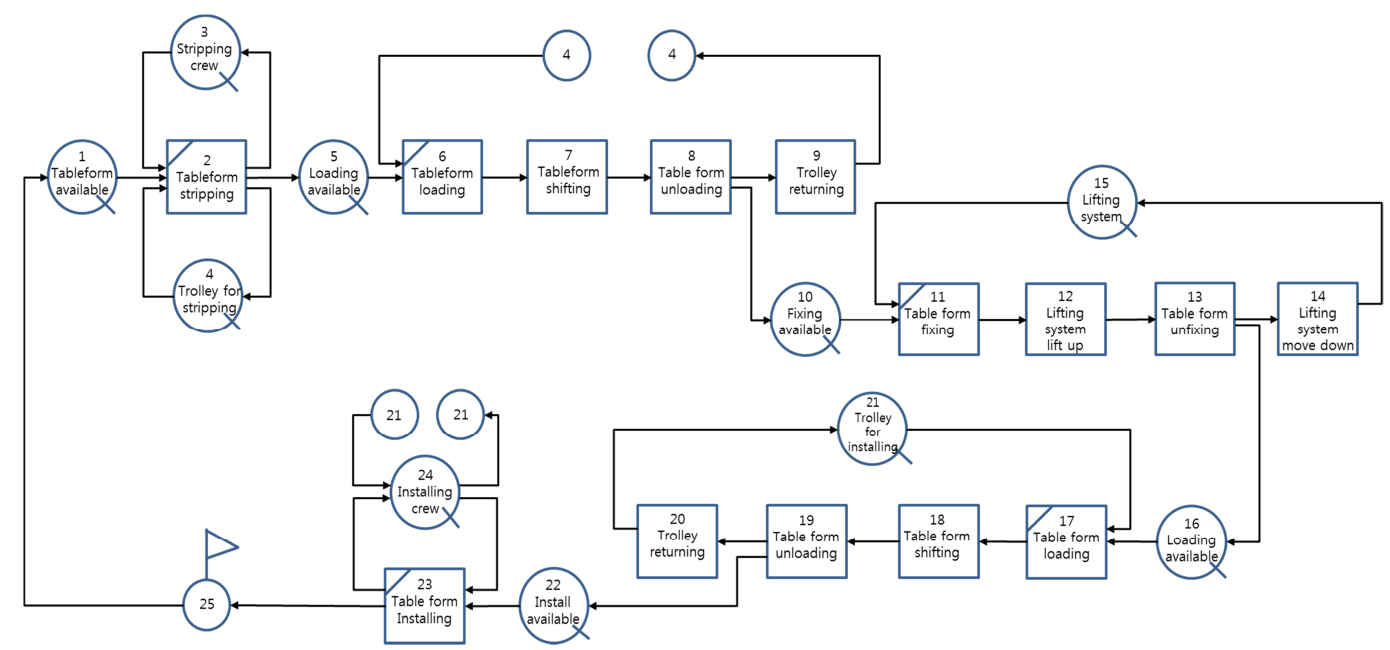

Figure 4 - Simulation model for table formwork with TLS

The resources invested in each activity were input on the basis of data collected at the case site. Fifty-one units of table forms, a pair of installation crews, a pair of stripping crews, a TLS, two shifting trolleys for stripping, and two shifting trolleys for installation were put into the case site, according to zone A. For the working duration for this simulation, data was collected from cameras at the case site. The durations are shown in Table 2. 
Table 2 - Duration input data of Table formwork with TLS

\begin{tabular}{lllccc}
\hline \multirow{2}{*}{ Node } & Work task & Value type & \multicolumn{3}{c}{ Duration (min) } \\
\cline { 4 - 6 } & & Min & Mean & Max \\
\hline 2 & Table form stripping & Triangular & 1 & 2.24 & 3.83 \\
6 & Table loading & Deterministic & & 0.1 & \\
7 & Table form shifting & Uniform & 0.488 & & 5.126 \\
8 & Table form unloading & Deterministic & & 1 & \\
9 & Trolley returning & Uniform & 0.488 & & 5.126 \\
11 & Table fixing & Deterministic & & 0.5 & \\
12 & TLS lift up & Deterministic & & 1 & \\
13 & Table form unfixing & Deterministic & & 0.5 & \\
14 & TLS move down & Deterministic & & 1 & \\
17 & Table form loading & Deterministic & & 1 & \\
18 & Table form shifting & Uniform & 0.488 & & 5.126 \\
19 & Table form unloading & Deterministic & & 0.1 & \\
20 & Trolley returning & Uniform & 0.488 & & 5.126 \\
23 & Table form installing & Triangular & 3.65 & 4.88 & 6.33 \\
\hline
\end{tabular}

Stripping, shifting, installation, and the returning time for the trolleys are input with the same values as in the CYCLONE model of the table formwork with T/C, since the only change was in the lifting equipment. Also, the loading, unloading, fixing, and lifting times with the TLS, which have almost fixed durations with little variation, were input as deterministic values.

\section{RESULTS}

\section{Comparative analysis of productivity}

For sufficient convergence of the result values of the simulation, the simulation was performed for 1,000 cycles. The results of the analyses of table forms with T/C and TLS are described in Table 3. For the formwork with TLS, on the basis of productivity of $0.169947 \mathrm{cycles} / \mathrm{min}$, the whole simulation time was 5884.2 minutes, and the installation time for each table form was 5.9 minutes. Thus, the productivity of the table formwork with TLS increased by $170.68 \%$, compared to the table formwork with $\mathrm{T} / \mathrm{C}$, and the whole installation time of fifty-one table forms decreased by 3.53 hours.

Table 3 - Results of the comparative analysis of the productivity

\begin{tabular}{lllll}
\hline Equipment & $\begin{array}{l}\text { Total } \\
\text { simulation time } \\
(\mathrm{min})\end{array}$ & $\begin{array}{l}\text { Cycle } \\
\text { number } \\
\text { (time) }\end{array}$ & $\begin{array}{l}\text { Productivity } \\
\text { per time unit } \\
\text { (cycle/min) }\end{array}$ & $\begin{array}{l}\text { Total } \\
\text { installation time } \\
\text { (hour) }\end{array}$ \\
\hline Tower crane & 10043.2 & 1000 & 0.099569 & 8.53 \\
TLS & 5884.2 & 1000 & 0.169947 & 5.00 \\
\hline
\end{tabular}

The idle state analysis of the two items of lifting equipment is described in Table 4. In order to analyze the reason for the productivity change between the two items of lifting equipment, a comparative analysis was performed, with work that showed the highest idle state in the table formwork with T/C, and work in the same class in TLS. In the table formwork with T/C, the idle state of tying preparation (node 6) was the highest at $89.01 \%$, and in the equivalent node with TLS, the idle state of fixing preparation (node 10 ) was $0.0 \%$. According to the result of the analyses, it is considered that the tying preparation with T/C caused the idle state, because of the T/C being occupied, until the installation of the table form was done. In contrast, the tying preparation with TLS was able to have a shorter idle state for lifting the next table form, since the TLS was not occupied during the installation time, and the table forms were lifted independently. 
Table 4 - Idle state analysis of the two items of lifting equipment

\begin{tabular}{lllll}
\hline Equipment & Node & Name & $\begin{array}{l}\text { Idle state } \\
(\%)\end{array}$ & $\begin{array}{l}\text { Average } \\
\text { waiting time } \\
\text { (min) }\end{array}$ \\
\hline Tower crane & 6 & Strap available & 89.01 & 9.6 \\
TLS & 10 & Fixing available & 0.14 & 0.0 \\
\hline
\end{tabular}

\section{Sensitivity analysis}

Sensitivity analyses of the two different formworks were conducted, to analyze the total installation time and lease fees, according to the change of equipment. The leasing fees for the trolley and TLS were calculated through interviews with construction-equipment experts. The leasing fee for $\mathrm{T} / \mathrm{C}$ was also estimated, by applying the lifting load factor for the table form, based on the leasing fee at a construction site where table formwork with a T/C was performed. The leasing fee for one T/C was $11,400,000$ won for one month. However, the leasing fee for the T/C was estimated as 4,332,000 won, because the lifting load factor was calculated as $38 \%$. The leasing fees for the equipment are described in Table 5.

Table 5 - Lease fee of equipment

\begin{tabular}{llll}
\hline Equipment & $\begin{array}{l}\text { Lease fee per } \\
\text { month } \\
(\text { won })\end{array}$ & $\begin{array}{l}\text { Period } \\
\text { (month) }\end{array}$ & $\begin{array}{l}\text { Total lease fee } \\
\text { (won) }\end{array}$ \\
\hline Trolley for installation & 450,000 & 18 & $8,100,000$ \\
$\left(E_{t i}\right)$ & & 18 & $8,100,000$ \\
Trolley for stripping $\left(E_{t s}\right)$ & 450,000 & 18 & $77,976,000$ \\
T/C $\left(E_{t c}\right)$ & $4,332,000$ & 18 & $126,000,000$ \\
TLS $\left(E_{t l s}\right)$ & $7,000,000$ & & \\
\hline
\end{tabular}

Based on the leasing fees for the equipment in Table 5, sensitivity analyses were conducted, by changing the number of trolleys for installation (1-4), trolleys for stripping (1-3), T/C (1-2), and TLS (1-2). The construction duration for a single floor was also classified into 3-day cycles and 4-day cycles. According to analysis of the tall building construction report and progress schedule, the total installation time of a table form in a 4-day cycle was variable, but within one day (6-10 hours). The installation time in the 3-day cycle was also variable, but within a half-day (4-6 hours). The results of the analysis are described in Table 6. 
Table 6 - Comparative result of the sensitivity analysis

\begin{tabular}{|c|c|c|c|c|c|c|c|c|c|c|}
\hline \multirow[t]{3}{*}{ Cycle } & \multirow{3}{*}{$\begin{array}{l}\text { Time } \\
\text { (hour) }\end{array}$} & \multicolumn{9}{|c|}{ Table formwork } \\
\hline & & \multicolumn{4}{|c|}{$\begin{array}{l}\text { Table formwork with T/C } \\
\left.\text { [T/C }\left(N_{t s}, N_{t c}\right)\right]\end{array}$} & \multicolumn{5}{|c|}{$\begin{array}{l}\text { Table formwork with TLS } \\
\left.\text { [TLS }\left(N_{t i}, N_{t s}, N_{t l s}\right)\right]\end{array}$} \\
\hline & & $N_{t s}$ & $N_{t c}$ & $\begin{array}{l}\text { Total } \\
\text { installation } \\
\text { time (hour) }\end{array}$ & $\begin{array}{l}\text { Total Cost } \\
\text { (won) }\end{array}$ & $N_{t i}$ & $N_{t s}$ & $N_{t l s}$ & $\begin{array}{l}\text { Total } \\
\text { installation } \\
\text { time (hour) }\end{array}$ & $\begin{array}{l}\text { Total Cost } \\
\text { (won) }\end{array}$ \\
\hline \multirow{6}{*}{$\begin{array}{l}\text { 4-day } \\
\text { cycle }\end{array}$} & $8 \sim 10$ & 1 & 1 & 9.37 & $86,076,000$ & 1 & 1 & 1 & 10.01 & $142,200,000$ \\
\hline & & 2 & 1 & 8.53 & $94,176,000$ & 2 & 1 & 1 & 9.93 & $150,300,000$ \\
\hline & & 3 & 1 & 8.51 & $102,276,000$ & 3 & 1 & 1 & 9.94 & $158,400,000$ \\
\hline & $6 \sim 8$ & & & & & 1 & 2 & 1 & 7.56 & $150,300,000$ \\
\hline & & & & & & 1 & 3 & 1 & 7.57 & $158,400,000$ \\
\hline & & & & & & 1 & 3 & 2 & 7.54 & $284,400,000$ \\
\hline \multirow{4}{*}{$\begin{array}{l}\text { 3-day } \\
\text { cycle }\end{array}$} & $4 \sim 6$ & 2 & 2 & 5.13 & $172,152,000$ & 2 & 2 & 1 & 5.00 & $158,400,000$ \\
\hline & & 3 & 2 & 5.06 & $180,252,000$ & 3 & 2 & 1 & 4.99 & $166,500,000$ \\
\hline & & 4 & 2 & 5.08 & $188,352,000$ & 2 & 3 & 1 & 4.23 & $166,500,000$ \\
\hline & & & & & & 2 & 3 & 2 & 4.24 & $292,500,000$ \\
\hline
\end{tabular}

$N_{t s}=$ number of inputted trolleys for stripping; $N_{t i}=$ number of inputted trolleys for installation; $N_{t c}=$ number of inputted T/Cs; $N_{t l s}=$ number of inputted TLSs.

The productivity of the table formwork with T/C was greatly influenced when the number of $\mathrm{T} / \mathrm{Cs}$ and trolleys for stripping was equally increased (i.e. T/C $(1,1)$ versus T/C $(2,2))$. On the other hand, the productivity of the table formwork with TLS was substantially influenced by the number of trolleys for installation and stripping (i.e. TLS $(1,1,1)$ versus TLS $(2,2,1)$. The number of trolleys for stripping had a great effect on the productivity (i.e. TLS $(1,1,1)$ versus TLS $(1,2,1)$ ).

Considering the economic feasibility, the table formwork with $\mathrm{T} / \mathrm{C}$, in the case of the 4-day cycle process, was more economical than the table formwork with TLS (i.e. T/C $(1,1)$ versus TLS (1, $1,1))$. Additionally, the table formwork with TLS, when the 3-day cycle was conducted, was more economical than the table formwork with T/C (i.e. T/C $(2,2)$ versus TLS $(2,2,1)$ ).

\section{CONCLUSIONS}

This study suggested quantitative data for cost-efficient equipment input planning, by using Web-CYCLONE. Also, to draw the objective productivity, data from a case site was used. The simulation values determined the selection of lifting equipment according to the progress schedule. The results of this research will be utilized as a basis for cost-efficient equipment input planning.

\section{ACKNOWLEDGMENTS}

This research was supported by a grant (code\#09 R\&D A01) from the High-Tech Urban Development Program, funded by the Ministry of Land, Infrastructure, and Transport.

This research was supported by technical data kindly provided by DOKA GmbH.

\section{REFERENCES}

Kim, T. H. (2013). Advanced system formwork and construction planning model for tall building construction (Doctoral dissertation). Korea University, Seoul, Korea. 
Lim, H. S., Kim, T. H., Cho H. H., \& Kang, K. I. (2013). Formwork productivity analysis model for cost-efficient equipment operation, The $5^{\text {th }}$ International Conference on Construction Engineering and Project Management (ICCEPM 2013), Orange County, California.

DOKA GmbH (2011, October). Dokamatic table (999767002 en-GB) [Brochure].

http://www.doka.com/web/references/index.en.php\#461

Zhang, P., Harris, F. C., Olomolaiye, P. O., \& Holt, G. D. (1999). Location optimization for a group of tower cranes, Journal of construction engineering and management, 125(2), 115-122. Doi: 10.1061/(ASCE) 0733-9364 (1999) 125:2 (115) 